\title{
When the Need for Cognitive Structure does not Cause Heuristic Thinking: The Moderating Effect of the Perceived Ability to Achieve Cognitive Structure
}

\author{
Yoram Bar-Tal \\ Department of Nursing, School of Health Professions, Tel Aviv University, Tel Aviv, Israel. \\ Email: yoramb@post.tau.ac.il
}

Received January $10^{\text {th }}, 2010$; revised April 30 ${ }^{\text {th }}, 2010$; accepted May $4^{\text {th }}, 2010$.

\begin{abstract}
This research explores the hypothesis that the relationship between need for cognitive structure (NCS) and the use of cognitive biases is moderated by the perceived ability to achieve cognitive structure (AACS). NCS is defined as the extent of preference to use cognitive structuring vs. piecemeal processing as a means to achieve certainty. AACS refers to the extent to which individuals believe that they are able to use information processing processes (cognitive structuring or piecemeal) that are consistent with their level of NCS. To examine this hypothesis, Study 1 explored the effect of the NCS by AACS interaction on the use of confirmation bias. Study 2, demonstrated this effect on the use of framing heuristic. The results of the two studies confirm the hypothesis.
\end{abstract}

Keywords: Need for Cognitive Structure, Ability to Achieve Cognitive Structure, Confirmation Bias, Framing Heuristics

\section{Introduction}

The idea that human information processing can be characterized by shortcuts which, although normally efficient and powerful, may lead to biases or errors that systematically deviate from some accepted norm or standard, dominates the study of cognitive and social psychology in the last two decades. These shortcuts include a variety of phenomena such as framing, causal schemata and confirmation bias. Inherent in the explanations of these phenomena is the idea that such shortcuts serve as general simplifying strategies for complex cognitive tasks and enable people to make inferences from and predictions on the basis of such scanty and unreliable data as are available. These cognitive biases are often said to originate in the limitations of otherwise reasonable informationprocessors. There are, however, indications that these shortcuts are also related to more stable, trait-like characteristics. For example, it has been reported that the use of heuristics in negotiation was moderated by the need for cognitive closure [1,2]. Another study found relationships between Openness and judgmental accuracy [3]. The present paper centers on the need for cognitive structure (NCS) as the motivation force that may explain the occurrence of these cognitive shortcuts.
Cognitive structuring has frequently been regarded as the most efficient way of making sense of the world. Cognitive structuring can be defined as "the creation and use of abstract mental representations (e.g., schemata, prototypes, scripts, and stereotypes)-representations that are simplified generalizations of previous experiences" [4]. Cognitive structuring fulfills many functions in human information processing, such as the selection of information, avoidance of inconsistent information, or specific attendance to relevant information all of which are functional in achieving certainty. Finally, cognitive structuring may facilitate achieving certainty by adding previously stored information concerning the validity of the inference [5]. All these characteristics of cognitive structuring combine to offer the most efficient and relatively effortless way of gaining a sense of certainty and control over the situation [6].

While cognitive biases and heuristics are often portrayed as resulting from human cognitive shortcomings, so that the effects of motivational factors on them are not often explored, there is a wide body of research examining the effect of motivational factors on cognitive structuring. The motive that suggested to affect most information-processing behavior is the NCS. Thus, if the mecha- 
nism that explains heuristics and cognitive biases is cognitive structuring, individual differences in NCS are expected to be associated with the extent of use of these biases [7].

\subsection{The Need for Cognitive Structure}

NCS is presently defined as the extent of preference to use cognitive structuring as a means to achieve certainty. NCS has long been at the center of attention in psychological research $[4,6,8,9]$.

This conception shares the assumption that the cognitive processes used by high-NCS individuals to reduce uncertainty are "category based" $[10,11]$, non-systematic and heuristic. They prefer to use holistic and rapid processing, crudely differentiated categories black-and-white type solutions and over-simplified dichotomizations. Fiske [12] suggested that cognitive structuring is the cognitively easier default option when there is no reason to discredit the categorization.

In contrast, low-NCS individuals are believed to prefer to reduce uncertainty using "piecemeal" or "systematic processing", which are manifested in vigilant behavior, based on a systematic and effortful search for relevant information, its evaluation and unbiased integration $[13,14]$. It is important to note that NCS is often conceptualized as a dimension, which, at its high pole, predisposes individuals to use cognitive structuring to achieve certainty. At its low pole, however, it is not associated with indifference or low motivation to achieve certainty, but with a high tendency toward piecemeal processes [9].

Bar-Tal $[15,16]$, however, argued that people may not only differ in their need for cognitive structure but also in their perceived ability to achieve cognitive structure (AA CS), which is orthogonal to the need. Thus, the fact that some people prefer to reduce their uncertainty by cognitive structuring does not mean that they believe that they are able to do so. Similarly, other people's wish to reduce their uncertainty by means of piecemeal processes does not imply that they expect themselves to be able to do so. That is, according to Bar-Tal, AACS moderates the NCScognitive structuring relationship.

\subsection{The Perceived Ability to Achieve Cognitive Structure}

AACS refers to the extent to which individuals believe that they are able to employ information processing processes (cognitive structuring or piecemeal) that are consistent with their level of NCS. That is, in case of high need of cognitive structure: 1) to avoid information that either cannot be categorized or clashes with their existing knowledge, and/or 2) to organize their knowledge to fit an already existing cognitive structure. In the case of low NCS this implies the extent to which they believe that they are able to actively and systematically comprehend, evaluate and integrate all useful information.

This conceptualization suggests that for high-AACS people, low NCS will probably be associated with individuating process, and high NCS with cognitive structuring. In contrast, for low-AACS people, low NCS implies that they do not expect themselves to be able to achieve certainty using piecemeal processing. Therefore they will revert to low piecemeal, effortless processing. This postulate is consistent with Chaiken, Giner-Sorolla and Chen [17] who suggest that accuracy motivation (low NCS) does not always lead to systematic processing (piecemeal process) since the latter can only take place if there is an adequate capacity to process information. Chaiken., et al. [17] furthermore suggest that when systematic processing is difficult or impossible, an accuracy-motivated person may have no choice but to base a decision on the best rule of thumb available. The present model, however, suggests that the perception of inability is sufficient to explain the tendency to avoid systematic processing.

Low-AACS/high-NCS individuals, who prefer to use cognitive structuring but do not expect themselves to be able to do so, settle for more effortful processes. According to the present model, a state in which a person with a high need for structure feels that he/she lacks or is unable to use the structure that would enable him/her to organize the available information, causes less efficient and more effortful individuating processing. The idea that high NCS may, under certain circumstances, be connected to intensive bottom-up vigilant information search, rather than the more predictable effortless "category based", non-systematic, is consistent with Janis and Mann's [14] description of the hyper-vigilant decision-maker, accordingly, hyper-vigilance is associated with indecisiveness, over-alertness and the uncontrollable search for additional information. Bar-Tal [15] proposed that this behavior pattern stem from these people's wish to reach an unqualified decision (high NCS), and their perceived inability to achieve the desired certainty by means of cognitive structuring. Note that while low-AACS/high-NCS people do not use cognitive structuring to achieve certainty, it does not mean that they use high piecemeal. Bar-Tal, Kishon-Rabin and Tabak, [16] suggested that there are differences between high piecemeal and hyper vigilance. For example, while high piecemeal is associated with a sensitivity to all relevant (hypothesis consistent and inconsistent information) hyper vigilance is associated in addition, with sensitivity to hypothesis irrelevant information.

Recently Bar-Tal and his colleagues $[15,16,18,19]$ provided empirical evidence in support of the notion of personal difference in AACS. Bar-Tal., et al. [16] also demonstrated the moderating effect of AACS on the relationship between NCS and cognitive structuring by using crude generalization and simplification as indices of cog- 
nitive structuring. It has to be noted that in these studies, the moderating effect of AACS on the relationship between NCS and cognitive structuring was demonstrated by means of a variety of operationalizations of NCS including Need for Cognition scale [20].

When applying the idea that cognitive structuring is affected by the interaction between NCS and AACS to the notion that cognitive structuring is the basic mechanism enabling cognitive biases and heuristics [7,21], one may hypothesize that the interaction will affect the use of biases and heuristics. The present paper consists of two studies that examine this hypothesis. Study 1 considers how the interaction between NCS and AACS affects participants' use of confirmation bias. Study 2 explores the interaction effect on the use of framing heuristic. We hypothesize that for low-AACS participants, an increase of NCS will be associated with a lower level of confirmation-bias and heuristic use. In contrast, for high-AACS participants, the increase of NCS will be associated with increased of confirmation-bias and heuristic use.

\section{Study 1}

One of the simplification strategies people use when testing a hypothesis is the confirmation bias. This bias is defined as the tendency to seek only corroborating evidence [22], and several types of it have been identified [23,24]. The present research centers on only one of them, namely, the tendency to avoid the examination of rival hypotheses. ${ }^{1}$ Baron., et al. [23] suggested that errors in hypothesis testing, such as those evident in confirmation bias, can be conceptualized as heuristics which come reasonably close, without actually calculating, to the normative model (as recommended by Popper [25] and others). The phenolmenon of confirmation strategies was validated in numerous studies $[23,26]$. Other researchers, however, have claimed that people use a diagnostic strategy rather than a confirmation strategy in hypothesis testing $[24,27,28]$ so that it can be concluded that people are capable of using both confirmatory as well as diagnostic strategies. It has also been suggested that the choice of confirmatory or diagnostic strategy depends on the nature of the task and of the instruction presented to the participants. Skov and Sherman [28], for example, suggested that asking participants about the utility of various kinds of available information focuses them on the diagnosticity of that information. Also, Devine, Hirt and Gehrke [27] noted that presentation of equally diagnostic hypothesis-true and alternative-true questions leads participants to a preference for hypothesis true question.

Replacing confirmation bias with a diagnostic strategy

\footnotetext{
${ }^{1}$ Baron, Beattie and Hershey [23] suggested three interrelated biases in hypothesis testing (congruence bias, information bias and certainty bias), of which congruence bias corresponds to the type of confirmation bias the present study centers on.
}

is of particular relevance in the case of medical diagnosis. In the medical profession diagnostic strategy is termed differential diagnosis (DD). The idea is that even when a physician, or a nurse, finds that symptoms A, B and C, which are very common in disease $\mathrm{X}$, are present, he/she cannot therefore safely infer that the patient suffers from disease $\mathrm{X}$ since $\mathrm{A}, \mathrm{B}$, and $\mathrm{C}$ may also be common in disease $\mathrm{Y}$. DD requires the search for symptoms $\mathrm{D}$ and $\mathrm{E}$ that are common in $\mathrm{Y}$ but do not characterize $\mathrm{X}$. Only when symptoms $\mathrm{A}, \mathrm{B}$ and $\mathrm{C}$ are present and $\mathrm{D}$ and $\mathrm{E}$ have not been found, the physician or nurse may be certain in his/her diagnosis that the patient suffers from $\mathrm{X}$ [29]. It has to be noticed however, that confirmation strategy can reveal certain errors in the hypothesis and does not necessarily lead to a mistaken conclusion: even searching only for symptoms A, B and C (a confirmatory strategy) may help to falsify the hypothesis if one or more of the symptoms is missing. A truly diagnostic strategy (examination of alternative explanations), however, would increase the validity of the inference by accounting for both necessary and sufficient conditions [26].

In the present context, people who use confirmation bias are driven by the need to achieve certainty in the validity of the hypothesis under consideration in an efficient and easy way. Alternative hypotheses may not only prolong the validation process and make it more effortful, but may in addition leave the individual uncertain regarding the validity of any of the hypotheses. That is, refutation of the original hypothesis by means of showing the feasibility of an alternative hypothesis does not prove the validity of the alternative. Achieving certainty in the validity of the alternative hypothesis would require examining it, in turn, against its alternative hypotheses. Therefore, a truly diagnostic strategy may not answer the need of those who are motivated to achieve certainty in an easy and fast way (high NCS). It is thus possible to suggest that confirmation bias is the result of a cognitive structuring process that allows people to achieve certainty with a low expenditure of effort by attending mainly to schema-consistent information while ignoring schemainconsistent or irrelevant information. Our hypothesis is that for low-AACS participants, the higher their NCS the more they will tend to use an individuating process and search for diagnostic (DD) information. In contrast, for participants with high AACS, the higher their NCS, the greater will be their use of schematic and heuristic processes and, therefore, the greater will be their use of confirmation bias (ignoring the diagnostic information).

\subsection{Method}

\subsubsection{Participants}

Participants were 55 registered nurses working in a hospital in Israel. Their mean age was $38.82(\mathrm{sd}=8.44)$ and their average tenure 15.52 years $(\mathrm{sd}=8.44)$. 


\subsubsection{Measures}

AACS Scale. The measure of AACS was carried out with a 24-item questionnaire. The items were chosen to represent manifestations of ease or difficulty in using cognitive structure (e.g., "Usually, I don't have afterthoughts upon making a decision"; "Even when I am really bothered by a decision I should make, I still find it hard to make up my mind and free myself from the hassle", respectively), or ease or difficulty in using piecemeal processes (e.g., "Usually I see to it that my work is carefully planned and well organized"; "Even if I make notes of things I have to do, it is hard for me to act upon them", respectively). In terms of construct validity of the AACS Scale, a high correlation between the R-S Scale [30] and AACS Scale was found $(\underline{r}=-0.56, \underline{p}<0.01)$. High score on the Scale represents high sensitivity and an inability to filter out schema (self-schemata) incongruent contents that is accompanied by motivation to maintain positive self-esteem and ego integrity. The R-S scale does not only represent inability to structure ego relevant contents. Hock, Krohne and Kaiser [31] argued that sensitizers do not tolerate uncertainty in general (high NCS) while being constantly and extensively preoccupied with enhanced information search. Therefore, a high R-S score corresponds to low AACS. Also, since AACS represents mastery of using the desired mode of information processing, and since self-efficacy should be strongly related to self-esteem, a positive relationship can be expected between AACS and self-esteem. Using Rosenberg's SelfEsteem Scale [32], such a relationship was indeed found $(\underline{r}=0.52, \underline{p}<0.01)$ in a sample of students. In addition, the AACS Scale was found to significantly correlate ( $\underline{\mathrm{r}}=$ 0.24, $\mathrm{p}<0.05$ ) with Cacioppo and Petty's Need For Cognition Scale [20]. In general, people with a high need for cognition prefer piecemeal processing and expend more effort in processing information [33,34]. Finally, the AACS Scale correlates negatively $(\underline{r}=-0.41, \underline{p}<0.01)$ with the Dysfunctional Impulsivity Scale [35]. Dickman defined impulsivity as the tendency to deliberate less than most people of equal ability before taking action; impulsivity was divided into functional and dysfunctional types. Functional impulsivity is the tendency to act with relatively little forethought when rapid response is required and/or there is little cost of error. That is, functional impulsivity can be viewed as the tendency to use cognitive structuring when this is the required process. Dysfunctional impulsivity was defined as the tendency to act with less forethought than most people of equal ability, with this tendency being a source of difficulty. Dysfunctional impulsivity can therefore be viewed as the tendency to use cognitive structuring when piecemeal process is required. ${ }^{2}$ Thus, to return to the found correlation between AACS Scale and the Dysfunctional Impulsivity Scale, a negative correlation indicates that the AACS Scale also measures the perceived ability to avoid cognitive structuring when piecemeal process required. ${ }^{3,4}$ Moreover, the notion that the AACS Scale represents the ability to use both piecemeal process as well as cognitive structuring when desired, was validated in another sample of students, where each functional and dysfunctional impulsivity Scale was found to made a significant contribution to the explanation of AACS, with a multiple R of 0.57 .

The test-retest correlation (with an interval of five weeks between measurements) was .86. Responses to the 24 items were on a 6-point Scale ranging from "Completely disagree” (1) to "\{Completely agree” (6). The composite AACS Scale score was the mean of responses to the 24 items (Cronbach's alpha = 0.82).

NCS Scale. NCS was measured by a 20-item questionnaire, with responses on a 6-point scale ranging from "Completely disagree" (1) to "Completely agree" (6). Items of the NCS were chosen to reflect specific personal preferences (e.g., "I am very annoyed when something unexpected disrupts my daily routine"; "I prefer things to be predictable and certain”), as well as general attitudes and values indicating preference for the unequivocal and absolute (e.g., "I don't like modern paintings in which I don't know what the painter meant"; "In order to get a good dish it is absolutely essential to follow the recipe exactly”). Items were selected so that they will reflect only motivation and preference, and not actual behavior, since the latter represents ability as well as need. ${ }^{5}$ The composite score was the mean of responses to the 20 items (Cronbach's alpha $=0.86$ ). The test-retest correlation (with an interval of five weeks between measurements) was 0.85 . In terms of construct validity, the NCS Scale was found to be positively correlated $(\underline{r}=0.43)$ with Rokeach's dogmatism Scale [36], $(\underline{r}=0.45)$ with the personal-need-for-structure Scale [4], and $(\underline{r}=0.68)$ with the need for closure Scale [37], which all represent constructs similar to NCS. Finally, given that the NCS Scale represents a dimension both of whose ends are related to high need for certainty (though each is achieved differently), and that need for certainty, in turn, should be correlated with need for control, a curvilinear relationship between desire for control and NCS could be predicted.

\footnotetext{
${ }^{2}$ For the relationship between impulsivity and cognitive structuring see Dickman [60] and Dickman and Meyer [61].

${ }^{3}$ Support for the notion that cognitive structuring is not the preferred method of high dysfunctional impulsives is its negative correlation $(\underline{r}=$ $-0.27, \mathrm{p}<0.01$ ) with NCS.

${ }^{4}$ It is interesting to note that the negative correlation between DI and AACS exists even after controlling for level of self-esteem $(\underline{r}=-0.35$, $\mathrm{p}<0.01)$. That is, the negative correlation between AACS and DI cannot be explained by the positive correlation between AACS and self- esteem.

${ }^{5}$ This was the original reason for constructing a new scale rather than using one of the already existing one. Only in a latter stage it was established that other existing scales that measure the same construct are not correlated with AACS.
} 
Indeed a significant curvilinear $(\underline{r}=0.25, \underline{p}<0.05)$, but not linear $(\underline{r}=0.06, \underline{p}=n s)$, relationship was found, between Burger and Cooper's [38] desire for control Scale and NCS Scales.

Stimuli Participants were presented with two written scenarios describing patients admitted to the emergency ward: one, a male with a suspected cerebrovascular accident (CVA), the other, a woman with abdominal pains indicating appendicitis. Each scenario was followed by 15 items suggesting possible tests needed to be done to achieve certainty in the diagnosis: positive answers on five of these tests confirmed the hypothesis (given diagnosis), five other items were diagnostic (positive answers pointed at the possibility that the differential diagnosis was correct) and five irrelevant. For the CVA scenario, a typical consistent item was "Checking for hemiparesis", a diagnostic item was "Is the patient taking medicines that are known to cause mental confusion?”, while an irrelevant item was, for instance: "Did the patient have rubella as a child?" Similarly, a consistent item with regard to the appendicitis scenario was "Is there a difference between the rectal and oral temperature?” A representative diagnostic item was "Is the patient known to suffer from gallstones?", while an irrelevant item was "Does the patient suffer from asthma?” All items were validated by a panel of two practitioners and three registered nurses.

The participants were asked to read each of the 15 suggested diagnostic questions that came with the scenarios, and to answer the following question: "To what extent can this test/question help you to decide whether the diagnosis is correct?" The reliability of the 10 consistent items was 0.81 , that of the diagnostic ones was 0.70 and that of the irrelevant information was 0.77 .

\subsubsection{Procedure}

Participants were approached at their working places by the experimenter who presented herself as a MA Nursing student and asked them to participate in a decision-making study. After completing the two tasks, they were requested to complete the AACS and NCS Scales. Upon completion participants were debriefed.

\subsection{Results and Discussion}

Since our main hypothesis relates to the moderating effect of the AACS $\times$ NCS interaction on confirmation bias, it is necessary first of all to establish the existence of confirmation bias. For this purpose, the mean ratings of consistent, irrelevant and diagnostic items were compared using a one-way ANOVA with repeated measure test. The analysis yielded a highly significant result $\left(\mathrm{F}_{(2,108)}=\right.$ $869.20, \mathrm{p}<0.01)$, with the mean of relevant items $(\underline{\mathrm{M}}=$ 5.67) being higher than that of the diagnostic items $(\mathrm{M}=$ 3.95), while the latter mean was higher than that of the irrelevant items $(\underline{\mathrm{M}}=1.52)$. The a posteriori Bonferoni
Table 1. Correlation among study 1 variables

\begin{tabular}{lccc}
\hline & 1 & 2 & 3 \\
\hline 1. AACS & 18 & & \\
2. NCS & -0.05 & 05 & \\
3. confirmation bias & 3.83 & 4.10 & 1.72 \\
mean & 66 & 70 & 86 \\
sd & & & \\
\hline
\end{tabular}

tests for dependent measures show that all the three measures differed significantly from each other. Thus, while participants clearly underestimated the utility of diagnostic information relative to hypothesis-consistent information, they nevertheless noticed that the diagnostic information was more informative than the irrelevant in formation. Hence, the data supported a predominant hy-pothesis-confirmation strategy, and a less strong, but nonetheless significant tendency to acknowledge the merit of diagnostic information. It is interesting to note that these findings were obtained in spite of the fact that the participants were requested to judge the utility of the test items for achieving certainty regarding the validity of the hypothesis. That is, Skov and Sherman's [28] suggestion that such a method leads to a subject's choice of diagnostic strategy is not supported by the present results.

To test the hypothesis, a confirmation bias index was constructed by subtracting the mean diagnostic items from the consistent items. Consequently, a higher score on the index represents greater extent of deviation from a diagnostic strategy. Next, the correlations among the study variables were calculated (see Table 1). Finally, a hierarchical regression was performed in which the two standardized main effects (AACS and NCS) where entered in the first step and the interaction term (AACS $\times$ NCS) was introduced in the second step. Following the suggestion of Dunlap and Kemery [39] concerning the reduction of multicollinearity, all variables were standardized before the respective cross-products were computed. The regression analysis as a whole was significant $\left(\mathrm{F}_{(3,51)}=3.22, \mathrm{p}<0.05\right)$, and only the interaction yielded a significant effect explaining $15 \%$ of the variance $(t=2.98$, $\mathrm{p}<0.01$ ). The final equation for confirmation bias is

$\mathrm{Y}^{\prime}=1.66-0.01 * \mathrm{~A}-0.08 * \mathrm{~B}+0.34 * \mathrm{AB}$, with A standing for NCS and B for AACS. To interpret the source of the interactions, regression lines of confirmation bias on NCS were calculated separately for high and low AACS according to one standard deviation below and above the mean. Since analyses were based on the z-scores of the independent variables, values were -1 and 1. Regression coefficients (b) were calculated using the equation obtained in the final step; the b of NCS was added to that of the interaction term after the latter was multiplied by either -1 or 1 [40]. 
In line with our hypothesis, the slope for the lowAACS participants was negative $(\underline{b}=-0.35)$, while it was positive for high AACS $(\underline{b}=0.33)$. That is, for lowAACS participants, higher NCS was associated with lower confirmation bias and higher use of diagnostic strategy. In contrast, for high-AACS participants higher NCS was associated with higher confirmation bias. Thus, this study demonstrated that the relationship between NCS and the use of cognitive biases is moderated by level of AACS. Finally, the findings show, in contrast to previous research, that the choice of confirmatory or diagnostic strategy is not determined by "cold" cognitive factors only, as mentioned earlier, but also by participants' epistemic motivation and their efficacy to satisfy this motivation.

\section{Study 2}

It is widely recognized that when making everyday judgments in uncertain situations people will very seldom use exhaustive statistical analysis to figure out the best choice. Rather, they often rely more pragmatically on simplifying judgmental strategies. These strategies, commonly termed heuristics, provide decision-making shortcuts as an alternative to the elaborate, more rational processes [41,44]. As it their function to achieve certainty in the easiest and quickest way by relying mainly on the most salient information, heuristics can be considered as manifestations of cognitive structuring processes. Indeed, Kruglanski and Freund [45] demonstrated that when people were motivated to achieve cognitive structure they showed a greater tendency to use the numerical anchoring heuristic [44]. Also, Henderson and Peterson [21] suggested that at least some of the framing heuristic scenarios are better explained by categorization processes.

Framing is one of the most commonly cited heuristic strategies. Tversky and Kahneman [46,47] proposed the concept of decision frame. When decision options are phrased in terms of gains, most people choose the risk averse option. But when options are phrased negatively in terms of losses, most people choose the risky option. This preference reversal relates to the alternative framing which causes people to view the outcomes as gains in the positive frame and as losses in the negative frame [46,47]. To account for the deviation of these results from the predictions of expected utility theory, Kahneman and Tversky [48] suggested the prospect theory. In prospect theory, the decision making process is divided into two phases: an editing phase in which the decision problem is edited into a simpler representation in order to make the second phase easier for the decision maker. The framing effect is mainly created in this second phase, which consists of an evaluation of the framed course of action for the final choice. Kahneman and Tversky [49] concluded that the use of framing heuristic is both pervasive and robust to the extent that it resembles perceptual illusions more than conceptual errors. In spite of ample research supporting Kahneman and Tversky's findings, recent research challenges their conviction by showing that the phenomenon is much more restricted than they suggested [50-53]. Fagley and Miller [51], for example, found no framing effect and Bier and Connell [50] even described a reversed framing effect. Wang and Johnston [53] demonstrated that the effect appeared only when describing a large-group context but not in a small group. Takemura [54] found that framing effect tends to disappear when participants are requested to justify their choice, to think about it, or when they have a long time for solving the problem. Finally, there are indications that framing effect is strongly affected by individual differences. Smith and Levin [55] established that framing effects are obtained for participants low in need for cognition but not for participants scored high on this Scale. Similarly, Shiloh, Salton and Sharabi [56] demonstrated that rational and intuitive thinking styles [57] are associated with framing effect.

One of Tversky and Kahneman's most famous examples of framing is the following "Asian disease" example [46].

Imagine that the United States is preparing for the outbreak of an unusual Asian disease expected to kill 600 people. Two alternative programs to combat the disease have been proposed. Assume that the exact scientific estimates of the consequences of the programs are as follows (the positive frame):

If Program A is adopted 200 people will be saved.

If Program B is adopted, there is a $1 / 3$ probability that 600 people will be saved and a $2 / 3$ probability that no people will be saved. Which of the two programs

Would you favor?

The other formulation of the programs (negative framing) included the following two options:

If Program C is adopted, 400 people will die.

If Program D is adopted, there is $1 / 3$ probability that nobody will die and

a 2/3 probability that 600 people will die (p. 453 ).

Tversky and Kahneman [46] indicated that the two versions induced different frames and therefore caused participants to adopt different decisions. Participants preferred program A over B (the risk averse response), but program D over program $C$ (the risk seeking response).

If our assumption that framing heuristic is a manifestation of cognitive structuring is correct, how can this phenomenon be attributed to simplification processes that are consistent with cognitive structuring? The explanation may be as follows: Participants seek the most positive or least negative consequence. However, when motivated to use cognitive structuring process, participants are also motivated to seek the simpler choice. Thus, in the posi- 
tively framed scenario, participants prefer program A because it is simpler (only positive consequences are mentioned), in contrast to program B which details both positive and negative consequences and requires calculations. In the negatively framed scenario participants avoid program $\mathrm{C}$ because it is clearly negative and by default (i.e., without considering it) they choose program D. Otherwise, they scan program $\mathrm{D}$, find the positive part of it (nobody will die), and disregarding the other elements of the option, they prefer it to the clearly negative option, program C. In line with this explanation, Kuhberger [52] demonstrated that the framing effect disappears when participants are presented with complete and mixed programs, i.e., 200 will be saved and 400 will not be saved, in program, A and 400 will die and 200 will not die in program C. That is, when there is no clear-cut program which enables simplification, the framing effect is not evident.

Since framing can be viewed as one of the manifestations of cognitive structuring processes, and since cognitive structuring is affected by the interaction between NCS and AACS, the present study hypothesizes that the use of framing will be moderated by the interaction between AACS and NCS. In other words, high-AACS participants will tend to use more framing the higher their NCS. In contrast, low-AACS participants will manifest negative correlation between their level of NCS and utilization of framing heuristic. The rationale for this hypothesis is that participants with high NCS will be more motivated to use the heuristic; however, those with low AACS will be able neither to sufficiently structure their cognition, nor to avoid inconsistent information, nor, indeed, to use heuristics for the sake of a quick and easy decision process.

\subsection{Method}

\subsubsection{Participants}

Participants were 51 women and 42 men whose average age was $39.12(\mathrm{sd}=13.02)$ and whose average years of formal education were 14.12 ( $\mathrm{sd}=2.70$ ); all participants agreed to participate in the study.

\subsubsection{Measures}

Need and ability to achieve cognitive structure. NCS and AACS were measured by scales described in Study 1 . The reliability of AACS was 0.80 and that of NCS was 0.89 .

Measure of framing effect. Participants were presented with a modification of Tversky and Kahneman's [46] "plague problem" i.e., they were requested to imagine that they returned a week ago from an exciting trip to the Far East. The Health Department declared that their experience from previous years showed that annually, 1800 people of all those who travel to the Far East were in- fected by a certain virus which does not cause an immediate symptom or health problem. A proper diagnosis enables cure of the disease. The Health Department announced that there are two kinds of tests to diagnose the disease, but neither is fully reliable. For the first test there is $1 / 3$ probability that 1800 people will be diagnosed correctly and $2 / 3$ probability that no one will be diagnosed correctly. For the second test, 600 people are diagnosed correctly. The introductory story of the negative version was similar to that of the positive one, the only difference being in the wording of the options, namely, in the first test 1200 people would not be diagnosed correctly, and in the second test, there was $1 / 3$ probability that none would be diagnosed incorrectly and 2/3 probability that 1800 people would not be diagnosed correctly. Having read each of the two scenarios participants were requested to rate the extent to which they would chose to be tested by each of the tests, on $100 \mathrm{~mm}$ visual analog scales ranging from "not all" (0) to "to a very large extent" (100). The positive and negative versions were separated by a fiveminute distraction task. The order of the two scenarios was counter balanced.

\subsubsection{Procedure}

Participants were told that the study examined various aspects of decision-making and that their anonymity would be preserved. Then they were requested to complete both versions of the framing scenarios as well as the intervening distraction task. Finally, they answered the 44 items of the AACS and NCS questionnaires.

\subsection{Results and Discussion}

To examine the effectiveness of the framing manipulation, a $2 \times 2$ within-subject ANOVA (gains vs. losses, and risk-aversion vs. risk-taking) was performed. The analysis yielded only a significant interaction effect $\left(\mathrm{F}_{(1,92)}=\right.$ 29.31, $\mathrm{p}<0.01)$. The a posteriori Tukey/b tests performed on the residuals [58] show that in problem 1 (framed as a gain), participants preferred the risk-aversion alternative (9.49) over the risk-taking one (-9.49). In contrast, in the case of problem 2 participants preferred the risk-taking option (9.49) over the risk aversion option (-9.49). Hence, the successfulness of the manipulation of the framing effect is highly evident.

To examine the study's main hypothesis, a total framing score was calculated by summing of the preference for risk-avoiding over risk-taking ratings in the first problem, and the preference for risk-taking over risk-avoiding ratings in the second problem. Subsequently, the correlations among the study variables were calculated (see Table 2). Finally, a hierarchical regression analysis was performed in whose first step the effects of AACS and NCS were introduced, while the second examined the interaction effect. The analysis shows that the regression as a whole was significant $\left(\mathrm{F}_{(3,85)}=3.00, \mathrm{p}<0.05\right)$, and only 
Table 2. Correlation among study 2 variables

\begin{tabular}{lccc}
\hline & 1 & 2 & 3 \\
\hline 1. AACS & & & \\
2. NCS & -0.01 & & \\
3.framing & -0.02 & 15 & \\
heuristic & 3.73 & 4.36 & 37.96 \\
mean & 65 & 83 & 67.61 \\
sd & & & \\
\hline
\end{tabular}

the interaction yielded a significant effect, explaining $9 \%$ of the variance $(\mathrm{t}=2.65, \mathrm{p}<0.01)$. The final equation for framing effect is

$$
\mathrm{Y}^{\prime}=34.18+7.88 * \mathrm{~A}+2.24 * \mathrm{~B}+18.61 * \mathrm{AB}
$$

with A standing for NCS and B standing for AACS.

The examination of the source of the interaction was performed as in Study 1.

In line with our hypothesis, while the slope of total framing effect for the low-AACS participants was negative $(\underline{b}=-10.73)$, it was positive for high AACS $(\underline{b}=$ 26.49). Thus, as predicted, while high AACS participants tended to use more framing heuristic the higher their level of NCS, low-AACS participants tended to use it less the higher their NCS.

The results from this study contradict Kahneman and Tversky's [49] claim regarding the robustness of the phenomenon of framing heuristic. If there are substantial amounts of people who tend to avoid the use of framing, it is not reasonable to view the framing effect as perceptual illusion. The present results cannot moreover be explained in terms of the prospect theory. Therefore, Tversky and Kahneman's [46] conviction that the framing phenomenon is best explained by prospect theory stands challenged. This study joins the other studies, mentioned earlier, that show the limitations of the phenomenon as well as the limitations of prospect theory's capacity in explaining this phenomenon. In addition, this study contributes in that rather than emphasizing either cognitive (mentioned above), or motivational factors [50,55,57] that effect the framing phenomenon, it demonstrates that framing, like other heuristic and cognitive biases, is influenced by a combination of motivational and cognitive factors.

\section{General Discussion}

The present paper hypothesized that cognitive biases are affected by the interaction between NCS and AACS. The results of the two studies validated this hypothesis. Study 1 showed that AACS moderates the NCS-confirmation bias relationship: higher NCS is associated with less confirmation bias (greater use of hypothesis inconsistent information). In contrast, for high-AACS participants, higher NCS goes with greater confirmation bias. Study 2 shows that while for high-AACS participants, the level of NCS is positively associated with the use of framing heuristic, for low-AACS participants, the level of NCS is negatively associated with framing heuristic.

The present results further validate our view that cognitive structuring, manifested in the present study by the use of cognitive biases and stereotyping, is affected by both NCS and AACS and not by NCS alone. This conclusion highlights the importance of distinguishing between the two constructs. In addition, the fact that in the two different samples, the correlations between NCS and AACS were found to be very low and non-significant not only supports this conclusion but also indicates that the two measures of AACS and NCS reflect different constructs.

The two studies are based on the assumption that the basic mechanism underlying cognitive biases is similar to that of motivational biases and that both of them are manifestations of cognitive structuring. From this point of view, the present results validate Kruglanski and his colleagues' $[7,45,59]$ claim that both cognitive and motivational biases are manifestations of the same epistemic motivational processes. Our present results however, depart from Kruglanski's lay epistemology theory in one important respect, namely that according to our conception people are not always able to adapt information processing processes (cognitive structuring or piecemeal; freezing or unfreezing, in lay epistemology terms) whenever they wish or need it.

To conclude, the present paper suggests that heuristic thinking cannot be explained by the mere motivation for simplified, relatively homogeneous, well-defined and distinct structures. Rather we suggest that the relation between this motivation and schematic thinking is moderated by the efficacy to achieve cognitive structure.

\section{REFERENCES}

[1] C. K. De Dreu, S. L. Koole and F. L. Oldersma, "On the Seizing and Freezing of Negotiator Inferences: Need for Cognitive Closure Moderates the Use of Heuristics in Negotiation,” Personality and Social Psychology Bulletin, Vol. 25, No. 3, 1999, pp. 348-362.

[2] L. A. Kurdek, "Relation between Neuroticism and Dimensions of Relationship Commitment: Evidence from Gay, Lesbian, and Heterosexual Couples," Journal of Family Psychology, Vol. 11, No. 1, 1997, pp. 109-124.

[3] R. A. Lippa and J. K. Dietz, “The Relationship of Gender, Personality and Intelligence to Judges' Accuracy in Judging Strangers' Personality from Brief Video Segments," Journal of Nonverbal Behavior, Vol. 24, No. 1, 2000, pp. 25-43.

[4] S. L. Neuberg and J. T. Newsom, "Personal Need for Structure: Individual Differences in the Desire for Simple Structure,” Journal of Personality and Social Psychology, 
Vol. 65, No. 1, 1993, pp. 113-131.

[5] S. T. Fiske and P. W. Linville, "What does the Schema Concept Buy us?” Personality and Social Psychology Bulletin, Vol. 6, No. 4, 1980, pp. 543-557.

[6] S. Bunder, "Intolerance of Ambiguity as a Personality Variable,” Journal of Personality, Vol. 30, No. 1, 1962, pp. 29-51.

[7] A. W. Kruglanski and I. Ajzen, "Bias and Error in Human Judgment,” European Journal of Social Psychology, Vol. 13, No. 1, 1983, pp. 1-44.

[8] S. Epstein, “Cognitive-Experiential Self Theory,” In: L. A. Pervin, Ed., Handbook of personality: Theory and Research, Guilford Press, New York, 1990, pp. 165-192.

[9] A. W. Kruglanski and D. M. Webster, "Motivated Closing of the Mind: 'Seizing' and 'Freezing'," Psychological Review, Vol. 103, No. 2, 1996, pp. 263-283.

[10] M. B. Brewer, “A Dual Process Model of Impression Formation,” In: T. K. Srull and R. S. Wyer, Eds., Advances in Social Cognition, Lawrence Erlbaum, New Jersey, Vol. 1, 1988, pp. 1-36.

[11] S. T. Fiske and M. A. Pavelchak, "Category-Based Versus Piecemeal-Based Affective Responses. Developments in Schema-Triggered Affect,” In: R. M. Sorrentino and E. T. Higgins, Eds., Handbook of Motivation and Cognition. Foundations of Social Psychology, Guilford Press, New York, 1986, pp. 167-203.

[12] S. Fiske, "Social Cognition and Social Perception," Annual Review of Psychology, Vol. 44, No. 1, 1993, pp. 155-194.

[13] S. Chaiken, A. Liberman and A. H. Eagly, "Heuristic and Systematic Processing Within and Beyond the Persuasion Context,” In: J. S. Ulman and J. A. Bargh, Eds., Unintended Thought, Guilford Press, New York, 1989, pp. 212-252.

[14] I. L. Janis and L. Mann, "Decision Making: A Psychological Analysis of Conflict, Choice, and Commitment," Free Press, New York, 1977.

[15] Y. Bar-Tal, "The Effect of Need and Ability to Achieve Cognitive Structure on Mundane Decision-Making,” European Journal of Personality, Vol. 8, No. 1, 1994, pp. 45-58.

[16] Y. Bar-Tal, L. Kishon-Rabin and N. Tabak, "The Effect of Need and Ability to Achieve Cognitive Structuring on Cognitive Structuring,” Journal of Personality and Social Psychology, Vol. 73, No. 6, 1997, pp. 1158-1176.

[17] S. Chaiken, R, Giner-Sorolla and S. Chen, "Beyond Accuracy: Defense and Impression Motives in Heuristic and Systematic Information Processing” In: P. M. Gollwitzer and J. A. Bargh. Eds., The Psychology of Action: Linking Motivation and Cognition to Behavior, Guilford Press, New York, 1996, pp. 553-578.

[18] Y. Bar-Tal and A. A. Guinote, "Who Exhibits More Stereotypical Thinking? The Effect of Need and Ability to Achieve Cognitive Structure on Stereotyping," European Journal of Personality, Vol. 16, No. 4, 2002, pp. 313-331.
[19] Y. Bar-Tal and A. Spitzer, "The Effect on Coping of Monitoring Blunting and the Ability to Achieve Cognitive Structure,” The Journal of Psychology, Vol. 133, No. 4, 1999, pp. 394-412.

[20] J. T. Cacioppo, and R. E. Petty, "The Need for Cognition,” Journal of Personality and Social Psychology, Vol. 42, No. 1, 1982, pp. 116-131.

[21] P. W. Henderson and R. Peterson, "Mental Accounting and Categorization Organizational,” Behavior and Human Decision Processes, Vol. 51, No. 1, 1992, pp. 92-117.

[22] J. Beattie and J. Baron, "Confirmation and Matching Biases in Hypothesis Testing," The Quarterly Journal of Experimental Psychology, Vol. 40, No. 2, 1988, pp. 269-297.

[23] J. Baron, J. Beattie and J. C. Hershey, "Heuristics and Biases in Diagnostic Reasoning: II. Congruence, Information, and Certainty," Organizational Behavior and Human Decision Processes, Vol. 42, No. 1, 1988, pp. 88-110.

[24] S. R. Evett, P. G. Devine, E. R. Hirt and J. Price, “The Role of the Hypothesis and the Evidence in the Trait Hypothesis Testing Process," Journal of Experimental Social Psychology, Vol. 30, No. 5, 1994, pp. 456-481.

[25] K. R. Popper, “Conjectures and Refutations,” Routledge and Kagan Paul, London, 1962.

[26] J. Klayman and Y. Ha, "Hypothesis Testing in Rule Discovery: Strategy, Structure and Content," Journal of Experimental Psychology: Learning Memory, and Cognition, Vol. 15, No. 4, 1989, pp. 596-604.

[27] P. G. Devine, E. R. Hirt and E. M. Gehrke, "Diagnostic and Confirmation Strategies in Trait Hypothesis Testing," Journal of Personality and Social Psychology, Vol. 58, No. 6, 1990, pp. 952-963.

[28] R. B. Skov and S. J. Sherman, "Information-Gathering Processes: Diagnosticity, Hypothesis-Confirmatory Strategies, and Perceived Hypothesis Confirmation,” Journal of Experimental Social Psychology, Vol. 22, No. 1, 1986, pp. 93-121.

[29] L. R. Van Wallendael and Y. Guignard, "Diagnosticity, Confidence, and the Need for Information," Journal of Behavioral Decision Making, Vol. 5, No. 1, 1992, pp. 25-37.

[30] D. Byrne, “The Repression-Sensitization Scale: Rationale, Reliability, and Validity,” Journal of Personality, Vol. 29, No. 3, 1961, pp. 334-349.

[31] M. Hock, H. W. Krohne and J. Kaiser, "Coping Dispositions and the Processing of Ambiguous Stimuli," Journal of Personality and Social Psychology, Vol. 70, No. 5, 1996, pp. 1052-1066.

[32] M. Rosenberg, "Society and the Adolescent Self Image," Princeton University Press, Princeton, 1965.

[33] R. F. Ahlering and L. D. Parker, "Need for Cognition as a Moderator of the Primacy Effect," Journal of Research in Personality, Vol. 23, No. 3, 1989, pp. 313-317.

[34] E. P. Thompson, S. Chaiken and D. Hazlewood, "Need for Cognition and Desire for Control as Moderator of Ex- 
trinsic Reward Effects: A Person X Situation Approach to the Study of Intrinsic Motivation,” Journal of Personality and Social Psychology, Vol. 64, No. 6, 1993, pp. 987-999.

[35] S. J. Dickman, "Functional and Dysfunctional Impulsivity: Personality and Cognitive Correlate,” Journal of Personality and Social Psychology, Vol. 58, No. 1, 1990, pp. 95-102.

[36] M. Rokeach, “The Open and Closed Mind: Investigation into the Nature of Belief System and Personality System," Basic Books, New York, 1960.

[37] A. W. Kruglanski, D. M. Webster and A. Klem, "Motivated Resistance and Openness to Persuasion in the Presence or Absence of Prior Information," Journal of Personality and Social psychology, Vol. 65, No. 5, 1993, pp. 861-876.

[38] J. M. Burger and H. M. Cooper, "The Desirability of Control," Motivation and Emotion, Vol. 3, No. 4, 1979, pp. 381-393.

[39] W. P. Dunlap and E. R. Kemery, "Failure to Detect Moderating Effects: Is Multicollinearity the Problem?” Psychological Bulletin, Vol. 102, No. 3, 1987, pp. 418-420.

[40] J. Cohen and P. Cohen, "Applied Multiple Regression/Correlation Analysis for Behavioral Sciences,” 2nd Edition, Lawrence Erlbaum, Hillsdale, New Jersey, 1983.

[41] D. Kahneman, P. Slovic and A. Tversky (Eds.), "Judgment under Uncertainty: Heuristics and Biases,” Cambridge University Press, Cambridge, 1982.

[42] D. Kahneman and A. Tversky, "Subjective probability: A judgment of Representativeness,” Cognitive Psychology, Vol. 3, No. 3, 1972, pp. 430-454.

[43] A. Tversky and D. Kahneman, "Availability: A Heuristic for Judging Frequency and Probability,” Cognitive Psychology, Vol. 5, No. 2, 1973, pp. 207-232.

[44] A. Tversky and D. Kahneman, "Judgment under Uncertainty: Heuristics and Biases,” Science, Vol. 185, No. 4157, 1974, pp. 1124-1131.

[45] A. W. Kruglanski and T. Freund, "The Freezing and Unfreezing of Lay Inferences: Effect on Impersonal Primacy, Ethnic Stereotyping, and Numerical Anchoring,” Journal of Experimental Social Psychology, Vol. 19, No. 5, 1983, pp. 448-468.

[46] A. Tversky and D. Kahneman, "The Framing of Decisions and the Psychology of Choice," Science, Vol. 211, No. 4481, 1981, pp. 453-458.

[47] A. Tversky and D. Kahneman, "Rational Choice and the Framing of Decisions," Journal of Business, Vol. 59, No. 4, 1986, pp. 251-278.

[48] D. Kahneman and A. Tversky, "Prospect Theory: An Analysis of Decision under Risk,” Econometrica, Vol. 47,
No. 2, 1979, pp. 263-291.

[49] D. Kahneman and A. Tversky, "Choices, Values, and Frames,” American Psychologist, Vol. 39, No. 4, 1984, pp. 341-350.

[50] V. M. Bier and B. L. Connell, "Ambiguity Seeking Multi-Attribute Decisions: Effects of Optimism and Message Framing," Journal of Behavioral Decision Making, Vol. 7, No. 3, 1994, pp. 169-182.

[51] N. S. Fagley and P. M. Miller, "The Effects of Decision Framing on Choice of Risky vs Certain Options," Organizational Behavior and Human Decision Processes, Vol. 39, No. 2, 1987, pp. 264-277.

[52] A. Kuhberger, "The Framing of Decisions: A New Look at Old Problems," Organizational Behavior and Human Decision Processes, Vol. 62, No. 2, 1995, pp. 230-240.

[53] X. T. Wang and V. S. Johnston, "Perceived Social Context and Risk Preference: Are-Examination of Framing Effects in A Life-Death Decision Problem," Journal of Behavioral Decision Making, Vol. 8, No. 4, 1995, pp. 279-293.

[54] K. Takemura, "The Effect of Decision Frame and Decision Justification on Risky Choice,” Japanese Psychological Research, Vol. 35, No. 1, 1993, pp. 36-40.

[55] S. M. Smith and I. P. Levin, "Need for Cognition and Choice Framing Effects," Journal of Behavioral Decision Making, Vol. 9, No. 4, 1996, pp. 283-290.

[56] S. Shiloh, E. Salton and D. Sharabi, "Individual Differences in Rational and Intuitive Thinking Styles as Predictors of Heuristic Responses and Framing Effect," Personality and Individual Differences, Vol. 32, No. 3, 2002, pp. 415-429.

[57] S. Epstein, R. Pacini, V. Denes-Raj and H. Heier, "Individual Differences in Intuitive-Experiential and Analytical-Rational Styles,” Journal of Personality and Social Psychology, Vol. 71, No. 2, 1996, pp. 390-405.

[58] R. L. Rosnow and R. Rosenthal, "Definition and Interpretation of Interaction Effects,” Psychological Bulletin, Vol. 105, No. 1, 1989, pp. 143-146.

[59] A. W. Kruglanski, "Lay Epistemics and Human Knowledge: Cognitive and Motivational Bases,” Plenum, New York, 1989.

[60] S. J. Dickman, "Impulsivity and Perception: Individual Differences in the Processing of the Local and Global Dimensions of Stimuli," Journal of Personality and Social Psychology, Vol. 48, No. 1, 1985, pp. 133-149.

[61] S. J. Dickman and D. E. Meyer, "Impulsivity and SpeedAccuracy Tradeoffs Information Processing," Journal of Personality and Social Psychology, Vol. 54, No. 2, 1988, pp. 274-290. 